\title{
OFICINA DE COMPOSTAGEM COMO PRÁTICA DE EDUCAÇÃO AMBIENTAL
}

\section{ARTIGO ORIGINAL}

ALBUQUERQUE, Kleberson Almeida de ${ }^{1}$

DIAS, Thaiane Soeiro da Silva ${ }^{2}$

PIRES, Saimo do Rosário ${ }^{3}$

RABELO, Danilo Cezar ${ }^{4}$

ALBUQUERQUE, Kleberson Almeida de. Et al. Oficina de compostagem como prática de educação ambiental. Revista Científica Multidisciplinar Núcleo do Conhecimento. Ano 05, Ed. 08, Vol. 01, pp. 74-86. Agosto de 2020. ISSN: 2448-0959, Link de acesso: https://www.nucleodoconhecimento.com.br/educacao/oficina-decompostagem

\section{RESUMO}

Este trabalho apresenta um relato de experiência sobre a prática de compostagem na Escola de Atividade Complementar Fazendinha Esperança (EACFE), no município de Marituba, Pará. Objetivou-se apresentar a educação ambiental por meio da compostagem e da contextualização do problema socioambiental do município. Foram realizadas duas oficinas agroecológicas com grupos de alunos em anos letivos diversos, tendo a participação de crianças e adolescentes. Com base nas oficinas e

1 Licenciado em Pedagogia pela UNICID (2019), Bacharel em Teologia pela UNICESUMAR (2017) e Licenciando em Ciências Sociais pela UFPA (2021).

2 Doutoranda em Ciências Ambientais pelo PPGCA/UFPA, Mestre em Ciências Ambientais (2012), Graduada em Meteorologia pela UFPA (2008).

${ }^{3}$ Graduando em Ciências Naturais pela UFPA.

${ }^{4}$ Graduando em Engenharia de Materiais pela UFPA. 
na discursão teórico crítica com os alunos, foi possível esclarecer dúvidas e despertar o interesse dos envolvidos. Diante da conscientização sobre o aumento crescente da produção de resíduos sólidos no mundo e o ensino da prática de compostagem, os participantes firmaram compromisso de cuidar do meio ambiente.

Palavras-chave: prática de ensino, compostagem, educação ambiental, agroecologia.

\section{INTRODUÇÃO}

A agroecologia é uma ferramenta que tem grande impacto socioeconômico e ambiental (CAPORAL; COSTABEBER, 2004). Portanto, promove viabilidade econômica e relação comercial de grupos que tem o cultivo agrícola como principal fonte de renda. Assim, outro aspecto positivo da agroecologia é a compostagem, a qual promove o reaproveitamento dos materiais orgânicos que antes eram inutilizados e passam a serem vistos como fertilizantes naturais de grande potencial nutritivo para os cultivos, hortaliças e verduras (OLIVEIRA et al., 2004). Dessa forma, torna-se uma alternativa à produção sustentável sem prejudicar o meio ambiente e consequentemente a saúde.

Por outro lado, o lixo é um dos grandes problemas atuais na sociedade. De acordo com a Secretaria Municipal de Saneamento (SESAN), a cidade metrópole do Estado do Pará, Belém, produz uma média diária de 1.800 toneladas de lixo, o que representa cerca de 200 caminhões-caçamba totalmente cheios. Com o encerramento das atividades no lixão do Aurá, em 2015, foi criado um projeto de redirecionamento do lixo vindo da região metropolitana para o município de Marituba. No entanto, a localização do aterro sanitário apresenta sérios problemas ambientais.

O portal de notícias G1 do Grupo Globo (G1 PA, 2016) relatou algumas reclamações em decorrência do aterro sanitário: "Muita gente doente, muita gente se queixando, gente indo para o posto médico, outras procurando outros recursos, utilizando gel, passando álcool para amenizar o odor". Além disso, comerciantes e donos de balneários também foram afetados de forma negativa, esse cenário se dá pelo fato de os balneários se localizarem nas proximidades e da possibilidade de a água estar 
contaminada. Logo, a falta de gerenciamento dos resíduos sólidos viabiliza a fragilidade e riscos socioambientais ao município.

Neste contexto, a melhor forma de começar essa mudança é ensinar os valores, respeito à natureza, comportamentos e uma forma de vida sustentável, a pessoas em seus primeiros anos de vida escolar. Nessa etapa da vida elas estão prontos a aprender, então, ensiná-las é relevante, porque além de serem conduzidas a um novo conhecimento, a probabilidade de que elas assumam atitudes de respeito e amor pelo meio ambiente e muito maior, visto que este período é à base das aprendizagens humanas (PICCININ, 2012).

Os educandos precisam ter seu futuro garantido neste planeta, garantia esta que a sociedade atual não tem proporcionado como recentemente foi denunciado pela UNICEF (2020), "O mundo não consegue proporcionar às crianças uma vida saudável e um clima adequado para o seu futuro". Desta forma, nada é mais importante do que começar um trabalho de educação ambiental na educação básica com o objetivo de conscientizá-los pela preservação do meio ambiente.

\section{DESENVOLVIMENTO}

De acordo com o censo escolar de 2018, existem 79 escolas de educação básica em Marituba, atendendo a mais de 124435 residentes (IBGE 2010), com uma densidade populacional de 1214,53 habitantes por $\mathrm{km}^{2}$, elevada taxa de crescimento populacional, tendo ocupado lugar de destaque no ranking de favelização, devido ao crescimento desordenado da capital paraense, onde as cidades vizinhas que compõe a Região Metropolitana de Belém passaram a servir como cidades dormitórios por abrigarem aqueles que buscam moradias mais baratas (GIFFONI 2011). Em seu território até o início dos anos 2000, havia 8 (oito) ocupações principais, a maioria identificada como bairros atuais do município, a maior ocupação foi a chamada, Che Guevara (atual residencial Almir Gabriel). Em meio a esta realidade se tem o desafio de pensar em educação ambiental, de forma a alcançar este público. 
A Escola de Atividade Complementar Fazendinha Esperança (EACFE) desenvolve educação continuada para crianças no contra turno escolar, oferecendo complementação escolar, oficinas de esportes, capoeira, jiu-jitsu, dança e práticas de agricultura urbana. Teve seu início como um projeto para atender as crianças em vulnerabilidade socioeconômica de bairros periféricos no município de Marituba, idealizado pela voluntária alemã Huberta Von Galen e inaugurado no dia 17 de abril de 2004, é umas das unidades do Centro Educacional e Social de Marituba (CESM), pertencente ao Instituto Pobres Servos da Divina Providência (IPSDP), a qual é uma instituição filantrópica religiosa sediada na Itália que desenvolve ações de educação e assistência em vários países do mundo.

Assim, a EACFE atende a mais de 120 crianças e adolescentes todos os dias, com idades entre 4 e 14 anos, em situação de vulnerabilidade social, e frequentam o ensino fundamental ou médio em escolas públicas. Os atendidos passam 4 horas por dia em várias atividades educacionais e recreativas e recebem duas refeições por dia. Uma das práticas de ensino para crianças é uma aula prática de agricultura. A EACFE possui um parque agroecológico, com horta, viveiro de mudas, e casa de compostagem, onde consegue produzir alimentos que complementam a comida das crianças e também é capaz de aumentar a renda da escola, vendendo produtos excedentes para famílias que participam do projeto de aeróbica.

Destacamos, pois, a educação ambiental é um direito de todos e deve ser garantida pela cooperação entre o estado e a sociedade, é determinada pela Lei Federal oㅡ 9795, de 1999, que estipula a Política Nacional de Educação Ambiental. Em seu Artigo $5^{\circ}$ aponta a necessidade de que,

O estímulo e o fortalecimento de uma consciência crítica sobre a problemática ambiental e social (III); O incentivo à participação individual e coletiva, permanente e responsável na preservação do equilíbrio do meio ambiente, estendendo-se a defesa da qualidade ambiental como um valor inseparável do exercício da cidadania (IV); O fortalecimento da cidadania, autodeterminação dos povos e solidariedade como fundamentos para o futuro da humanidade (VII) (BRASIL, 1999). 
De modo geral, a EACFE possui uma vasta experiência na prática de educação ambiental e é uma referência para recomendações de ações municipais e estaduais, como o projeto Quintais Produtivos, que fomentou a criação do Projeto Quintais Amazônicos Maritubenses, o qual recebeu o reconhecimento estadual de Destaque Prata em Educação profissionalizante no Prémio SEBRAE de Educação Empreendedora do clico de 2018 (SEBRAE, 2019). Tais projetos foram idealizados pela engenheira agrônoma Antônia do Socorro Aleixo Barbosa, que é Mestre em Agronomia pela Universidade Federal Rural do Pará. Atualmente ela está à frente da Diretoria de Agricultura Familiar da Secretaria de Estado de Desenvolvimento Agropecuário e Pesca (SEDAP). Em sua gestão na EACFE, vários projetos foram desenvolvidos e sugestões de educação ambiental foram apresentadas, incluindo a Esperança na terra, que forneceu a jovens e adultos, capacitações em floricultura e paisagismo, encaminhando um grande número para o mercado de trabalho. Ainda hoje, atua para esse fim em todas as suas frentes de trabalho profissional e social.

Mais recentemente, dois projetos voltados para a temática são desenvolvidos paralelamente pela EACFE sob sua coordenação. O Projeto Eco-Trilha, que visa despertar a consciência ambiental, onde o amplo espaço arborizado da EACFE é aberto para escolas e instituições locais terem acesso a reflexões e aprofundamentos em novas práticas sustentáveis, criando assim um local propício para educação ambiental. O segundo projeto, chama-se Quintais Produtivos, que capacita famílias da comunidade em agricultura urbana agroecológica, além de fomentar a coleta seletiva do lixo e compostagem (ALBUQUERQUE; BARBOSA; SILVA, 2018).

A fim de aproveitar o espaço oferecido pela EACFE e ressaltar a importância do dia Nacional do Meio Ambiente, como é salientado por Ferreira; Besen e Ubinski (2017, p. 12785), em consideração a este dia para exortar a luta contra as "injustiças sociais, envolvendo também aspectos relacionados ao ambiente em que vivem e os fatores que impactam na qualidade de vida das pessoas e de outros seres vivos", desta forma, foi oferecido aos educandos da EACFE a Semana do Meio Ambiente com oficina de compostagem e adubação agroecológica. Desta maneira, este trabalho se desenvolveu da seguinte forma: 
Na primeira oficina, ocorrido no dia 04/06/2019, das 08:00 às 10:00 horas da manhã, realizou-se o debate sobre compostagem de resíduos sólidos orgânicos, tendo sua relevância destacada por Peres e Judice (2017, p. 13), ao apontarem a "importância de reciclar os resíduos orgânicos, sendo a compostagem como uma forma fácil, viável e sustentável de reutilizar esses resíduos". Neste intuito, foram atendidas duas turmas de crianças e adolescentes, uma subsequente a outra, o tempo médio foi de 60 minutos para cada oficina.

O trabalho começou com uma roda de conversa abordando a definição de compostagem, um método relevante para Paiva; Araújo e Cruz $(2019$, p. 86), pois afirmam a importância de "que a roda de conversa seja percebida como um dos lugares de encontro da educadora e das crianças, um espaço democrático e de participação". Logo depois, foram introduzidos os materiais utilizados no processo orgânico, exemplos das folhas, restos de legumes, verduras e frutas, dentre outros. Por conseguinte, discutimos como a pilha de compostagem é organizada e como a mistura influencia para o processo de decomposição aeróbica, explicando que a decomposição é um processo de ciclo natural em condições aeróbias. Dessa forma, a partir da transformação de todo esse material orgânico forma-se o húmus (adubos), rico em nutrientes e sais minerais, e pode ser usado na agricultura, mas também em hortas e jardins.

Após a explicação, foi realizado um breve debate sobre a situação dos resíduos domésticos e a implantação de aterros sanitários, o que trouxe grandes problemas sociais e ambientais aos moradores de Marituba, destacando a importância da Educação Ambiental através da conscientização sobre o consumismo, poluição e degradação ambiental, indagando sobre possíveis soluções para essa problemática, partindo inicialmente do indivíduo, para que em fim, tal consciência se propague na coletividade. Como é apresentado por Berna (2005, p. 18),

Existem pessoas que consideram mais fácil reclamar que ninguém ajuda, mas não se perguntam se estão fazendo sua parte na defesa do planeta. Se quisermos que os demais modifiquem seus hábitos, em primeiro lugar precisamos modificar os nossos. Se queremos um planeta preservado de verdade, não basta apenas lutar contra poluidores e 
depredadores; é preciso também nos esforçar para mudar nossos valores consumistas, hábitos e comportamentos que desencadeiam poluição, bem como atitudes predatórias contra os animais, as plantas e o meio ambiente.

A atividade se desenvolveu pedindo o comprometimento e possível aplicação da compostagem em suas residências e na comunidade em geral. Pois, de nada adiantaria uma educação ambiental que não considerasse as realidades da comunidade, assim como foi defendido por Sorrentino e Trajber (2007, p. 14),

A educação ambiental assume assim a sua parte no enfrentamento dessa crise radicalizando seu compromisso com mudanças de valores, comportamentos, sentimentos e atitudes, que deve se realizar junto à totalidade dos habitantes de cada base territorial, de forma permanente, continuada e para todos. Uma educação que se propõe a fomentar processos continuados que possibilitem o respeito à diversidade biológica, cultural, étnica, juntamente com o fortalecimento da resistência da sociedade a um modelo devastador das relações de seres humanos entre si e destes com o meio ambiente.

Como defendeu Freire (1987), a relação entre humanos e meio ambiente precisa ser redefinida através do uso de recursos naturais, apontando para a necessidade de desenvolver e lutar por um conhecimento mais crítico da realidade. Através da mudança de condições específicas, as pessoas podem avançar e procurar mudar a realidade. Portanto, é compreensível que a sociedade precise se equipar com ferramentas que Ihes permitam participar efetivamente na solução dos problemas sociais e ambientais que experimentaram.

Nessa oficina, encorajou-se a participação ativa dos educandos, para que não se tornassem meros destinatários de informações, mas pudessem ver criticamente 0 mundo e relação ambiental. A passividade no sistema educacional é criticado por Veloso (2007, p.78),

A organização que ainda prevalece em parte das escolas brasileiras continua refletindo uma concepção obsoleta de educação, de ser humano e de sociedade, em que o conhecimento é algo a ser transmitida, a aprendizagem é um acúmulo de informações, os conteúdos escolares são recortes do conhecimento científico arbitrariamente considerado relevante, os professores são os que transmitem, e os alunos são os que assimilam. Uma cadeia educativa 
linear, reprodutivista e violadora dos nossos direitos de sermos quem somos e vivermos nossa realidade e não a de outros.

Após importantes contribuições teóricas, a parte prática foi aplicada e todos os alunos foram levados para a casa de compostagem, onde observaram tudo o que estava envolvido durante a oficina, conforme a (Figura 1).

Figura 1. Casa da compostagem.

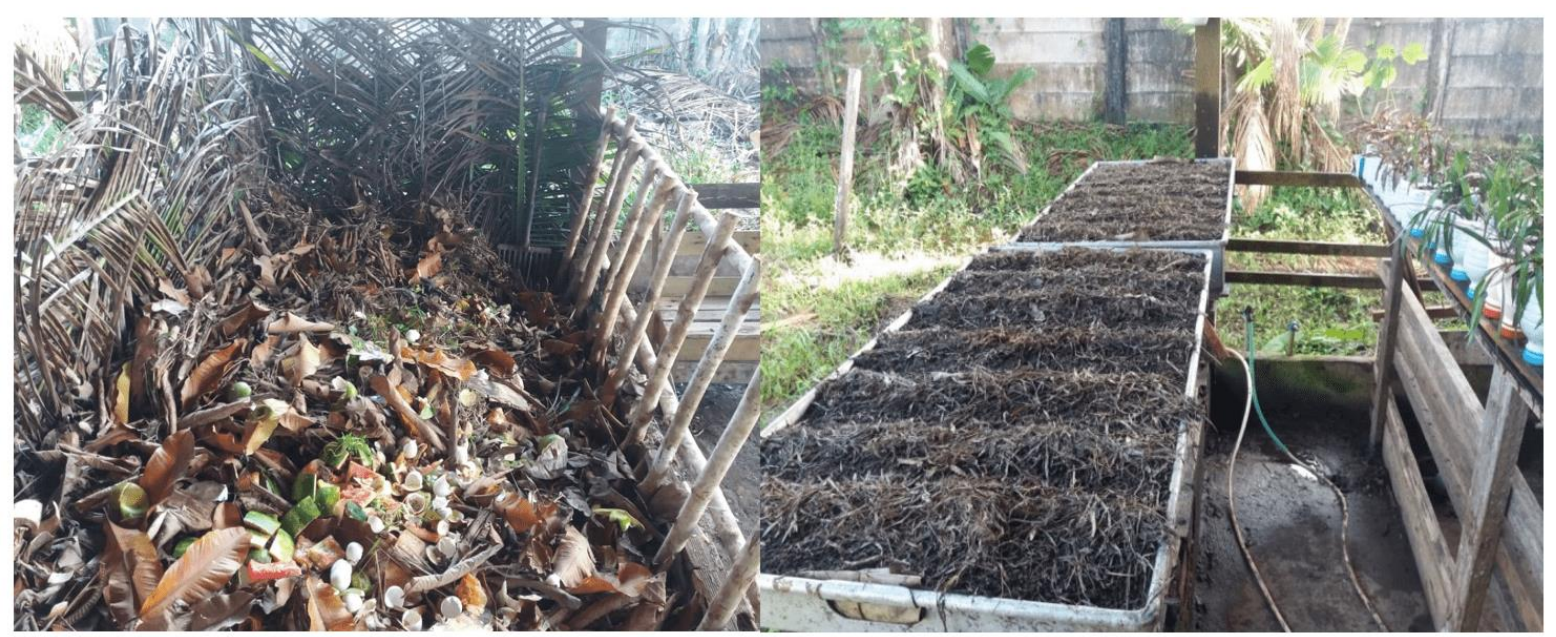

Fonte: ALBUQUERQUE, 2019.

Na segunda oficina, realizado no dia 06/06/2019, houve a finalização dos assuntos de compostagem. Continuando referindo-se aos dados relevantes do Ministério do Meio Ambiente (MMA), destacaram que 32 milhões de toneladas de resíduos orgânicos foram despejadas em aterros sanitários no Brasil. Quando essa substância acumulada se decompõe, vários gases são gerados e certos gases (como o gás metano), tornamse fatores que causam o efeito estufa. Foram apresentados também os dados da revista Nature, indicando que o planeta vai chegar ao pico do descarte de resíduos até $O$ ano de 2050 (HOORNWEG; BHADA-TATA; KENNEDY, 2013), onde será descartado em média 12 milhões de toneladas de lixo por dia tornado insustentável a vida do homem na terra. Desta forma, as questões ambientais e a devida atenção que os participantes devem receber ao entrar em contato com os resíduos são levantadas de maneira crítica. 
Em seguida, falou-se sobre o adubo orgânico que é o resultado final da compostagem, de sua eficácia e utilização no meio ambiente. Tendo em vista que, o substrato obtido no solo ajuda as plantas no seu desenvolvimento e assim o artifício não agride a natureza, pois não contém fertilizantes químicos. Destaca-se a adubação orgânica que resulta em dois importantes componentes: 1) sais minerais - contêm nutrientes para as raízes das plantas; e 2) húmus - cuja aplicabilidade consiste em melhorar as propriedades físicas, químicas e biológicas do solo.

Posteriormente, retornou-se para a casa de compostagem para observar e colher adubo orgânico, onde os alunos fizeram o plantio das sementes de Ipê-rosa $(\mathrm{H}$. heptaphyllus) e Aroeira-vermelha (Schinus terebinthifolia), conforme a (Figura 2). Todos participaram de forma ativa do plantio, lançou-se a pergunta para eles, sobre qual seria a importância de fazer o plantio com o adubo orgânico? E todos souberam responder que a semente iria crescer saudável e cheia de nutrientes naturais, a ação não é inorgânica e não contém fertilizantes químicos. Assim, percebeu-se a construção da consciência ambiental nos participantes ao compreenderem as bases da agroecologia, na prática da compostagem e a utilização de adubos orgânicos.

Figura 2. a) Participação de alunos na pilha da compostagem e b) Plantio das sementes de Ipê e Aroeira.

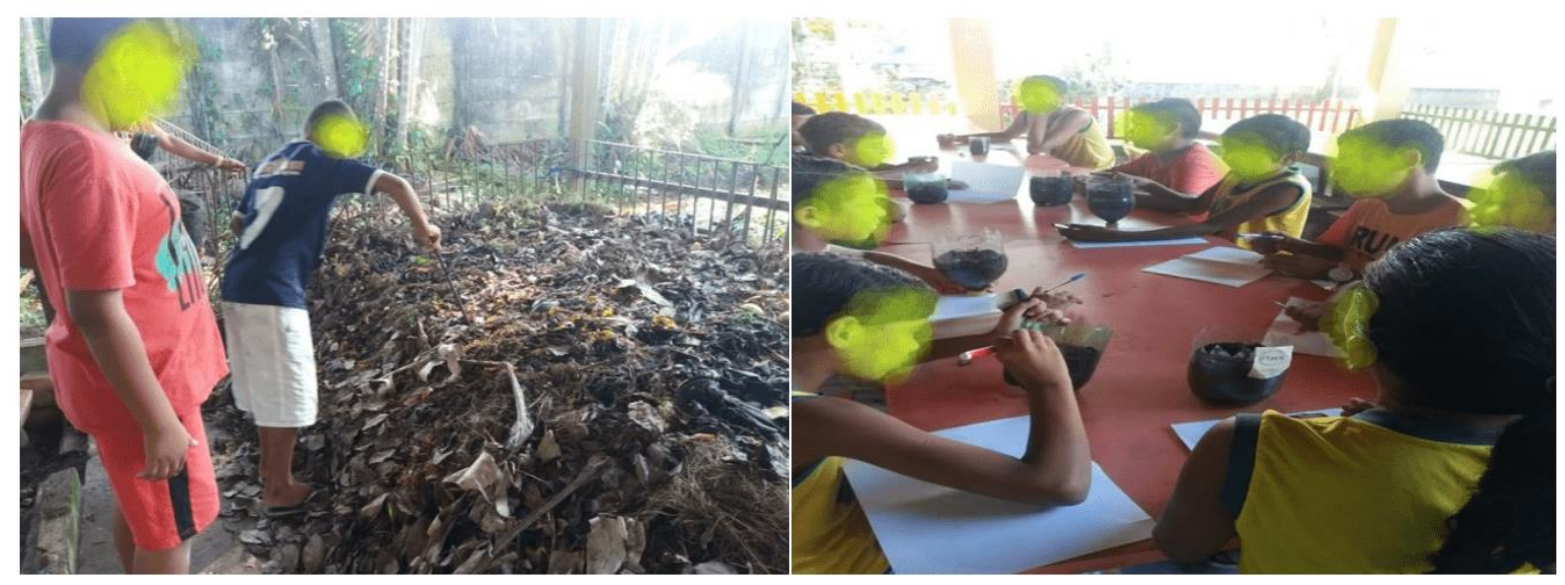

Fonte: ALBUQUERQUE, 2019.

As oficinas de compostagem de resíduos sólidos orgânicos, foram finalizadas no dia 06/06/2019, sendo a última atividade, os alunos participaram de uma dinâmica 
avaliativa do Que bom (algo que gostou) e Que tal (sugestão) e Que pena (algo desagradável) de Berkenbrock (2004). Esses puderam expressar suas opiniões e sugestões para as demais edições futuras, conforme o quadro abaixo:

Quadro 1 - Resposta do método Avaliativo.

\begin{tabular}{|l|l|l|}
\hline Que bom: & Que tal: & Que pena: \\
\hline $\begin{array}{l}\text { "Que pude aprender, "Continuar com as } \\
\text { mas de como cuidar do }\end{array}$ & $\begin{array}{l}\text { "Que alguns colegas } \\
\text { oficinas" }\end{array}$ & \\
meio ambiente através & & \\
da compostagem de & & \\
resíduos sólidos & & \\
orgânicos" nas oficinas"
\end{tabular}

Nosso ponto de vista é que ao desenvolver esta oficina de compostagem e fertilizantes orgânicos com os alunos da EACFE, não apenas podemos estudar conceitos e princípios sociais e ambientais, mas também podemos desenvolver um processo que permite que indivíduos e gerações futuras da comunidade estabeleçam desenvolvimento que promova qualidade de vida, além de construir coletivamente conhecimentos necessários para seu desenvolvimento integral quanto ao que tange sua vida em relação ao meio ambiente. Tendo assim, o processo como resultado objetivado, sendo parte importantíssima do que se esperava neste trabalho, como relata Portilho (2005, p. 176) ao afirmar que "Trata-se de privilegiar uma concepção que vê a participação em questões ambientais como um bem em si mesmo e não como um mero meio para se chegar a um fim". 
Os conhecimentos construídos em conjunto com as crianças nesta oficina, poderão contribuir para o desenvolvimento de atitudes sustentáveis em pequenas ações do seu dia-a-dia, a fim de que possam aplicar em suas casas o que aprenderam na EACF, através da realização de coleta seletiva e reciclagem de resíduos orgânicos úmidos para a construção de pilhas de compostagem, de modo que esta ação não fique apenas na escola, mas seja multiplicada nas casas, vizinhança, bairros e em toda a cidade, visando o enfrentamento da atual conjuntura ambiental vivenciada pelo município.

\section{CONSIDERAÇÕES FINAIS}

Por fim, deve-se ressaltar que o descarte inadequado do lixo causou grande tensão em nossos dias, onde é possível perceber a necessidade de que alguma medida seja tomada, sendo a aplicação da educação ambiental a mais importante de todas. Cuidar do meio ambiente não é apenas responsabilidade do governo, mas também é responsabilidade de toda a população. Pensar em gerenciamento de sustentabilidade vai muito além de refletir em meio ambiente ou apenas solucionar problemas socioeconômicos, requer a compreensão de que não se pode ver o meio desassociado do indivíduo, é preciso que cada homem e mulher do planeta se veja como responsável por nossa sociedade e como potencial transformador dela.

Quando olharmos para a natureza e percebermos o quanto precisamos do meio ambiente, entenderemos que a promoção da educação ambiental no espaço escolar é essencial para reduzir o impacto das pessoas no que tange a preservação do meio ambiente. Portanto, é necessário encontrar um método alternativo viável de educação ambiental, para que os alunos possam interagir de maneira substancial e não arbitrária para aprender significativamente na realidade.

Se métodos eficazes de ensino não forem utilizados, a educação ambiental será apenas mais um curso de transferência de conhecimento e repetição de conceitos, porém, através da prática de tornar os alunos autônomos na construção de seus conhecimentos, eles darão sentido e significado para a aplicação do que aprendem em suas vidas, como defendido por Pelicione (2000), tendo a educação ambiental 
uma perspectiva prática voltada para a formação integral dos educandos, possibilitando uma base teórica e cultural que possibilite a atuação crítica no que diz respeito às questões de cidadania e valorização do ambiente, superando os obstáculos existentes para o uso sustentável do meio pela sociedade nos estão inseridos.

As vivências desenvolvidas pelos alunos terão possíveis resultados em longo prazo, sob este despertamento de uma consciência ambiental, pois como Leff (2005) afirma, a educação ambiental adquire um sentido estratégico na condução do processo de transição para uma sociedade sustentável. Sendo assim, os alunos podem prestar atenção à proteção dos recursos naturais e à interação com a conservação natural por meio de medidas simples na vida cotidiana, como economia de água ao escovar os dentes ou tomar banho, economizar energia elétrica com menos tempo de televisão ou aparelhos eletrônicos, reciclagem de resíduos orgânicos e reutilização de matérias inorgânicas, sendo o lixo reutilizado como garrafas pet para a confecção de vasos, a fim de serem usados como vasos das plantas e os lixo úmido como adubo orgânico resultado da compostagem, totalizando medidas pautadas em soluções para problemas ambientais atuais e a garantia do acesso aos recursos naturais para as próximas gerações.

Levando em consideração o pouco tempo em que a oficina foi executada, pode ser considerada como bem sucedida. Foi proposto a EACFE que dessem seguimento no trabalho ao favorecer a descoberta do processo de decomposição na compostagem gradualmente, além de sua aplicação como adubo orgânico na horta que a escola possui e também incentivar seus alunos a darem continuidade em suas casas para uma nova forma de se relacionar com o lixo e com o meio ambiente. Podendo este projeto ser replicado em outras escolas devido sua eficácia, de modo a possibilitar estas vivências com práticas agroecológicas e a construção de uma consciência ambiental. 


\section{REFERÊNCIAS}

Albuquerque, K. A.; BARBOSA, A. S. A.; SILVEIRA, R. C. Projeto Ecotrilha: Prática de educação ambiental. In: Anais do Simpósio Internacional Interdisciplinaridade, Sustentabilidade e Desenvolvimento: crítica e atualização do debate na produção do conhecimento na Amazônia, Belém-PA, 2018.

ALBUQUERQUE, K. A.; BARBOSA, A. S. A.; SILVEIRA, R. C. Projeto quintais produtivos agroecológicos: Diagnóstico inicial. In: Anais do Simpósio Internacional Interdisciplinaridade, Sustentabilidade e Desenvolvimento: crítica e atualização do debate na produção do conhecimento na Amazônia, Belém-PA, 2018.

BERKENBROCK,V. J. Dinâmica para encontros de grupos. Petrólis: Vozes, 2004.

BERNA, V. S.D. Pesamento Ecológico: reflexões críticas sobre o meio ambiente, desenvolvimento sustentável e responsabilidade social. São Paulo: Paulinas, 2005.

BORTOLON, B.; MENDES, M. S. S. A Importância da Educação Ambiental para o Alcance da Sustentabilidade. Revista Eletrônica de Iniciação Científica. Itajaí, Centro de Ciências Sociais e Jurídicas da UNIVALI. v. 5, n.1, p. 118-136, 1ํㅜ Trimestre de 2014. Disponível em: <www.univali.br/ricc> - ISSN 2236-5044.

CAPORAL, F. R.; COSTABEBER, J. A. Agroecologia e extensão rural. Contribuições para a promoção do desenvolvimento rural sustentável. Brasília DF. MDAISAF\DATER-IICA, 2004.

DE BESSA ANTUNES, P. Direito ambiental. Rio de Janeiro: Lumen Juris, 2008.

Escola de atividade complementar Fazendinha Esperança. CESM, Marituba. Disponível em : < http://www.cesmmarituba.org.br> Acesso em: $15 / 06 / 2019$ 
FERREIRA, M. G.; BESEN, B. L.; UBINSKI, J. A. S. Dia mundial do meio ambiente: o pensar dos alunos. In: Anais do XIII Congresso Nacional de Educação EDUCERE, 2017.

FREIRE, P. Pedagogia do Oprimido. 17ª ed. Rio de Janeiro: Paz e Terra, 1987.

G1PA. Moradores reclamam do aterro sanitário em Marituba. G1-Pará, Belém. Disponível em: <g1.globo.com/pa/para/noticia/2016/06/moradores-reclamam-doaterro-sanitario-em-marituba.html> Acesso em 14/06/19.

GIFFONI, C. Belém cresce e incha cidades-dormitório. Valor Econômico, São Paulo, 22/12/2011. Disponível em: $<$ https://valor.globo.com/brasil/noticia/2011/12/22/belem-cresce-e-incha-cidadesdormitorio.ghtml>. Acesso em: 18/06/2020.

HOORNWEG, D.; BHADA-TATA, P.; KENNEDY, C. Waste production must peak this century. Reino Unido: Nature, 2013.

LEFF, H. Saber Ambiental: Sustentabilidade, Racionalidade, Complexidade, Poder. Petrópolis: Vozes, 2005.

OLIVEIRA, F. N. S.; LIMA, H. J. M,; CAJAZEIRA, J. P.. Uso da compostagem em sistemas agrícolas orgânicos. Fortaleza: Embrapa Agroindústria Tropical, 2004.

PAIVA, A. C. S. S.; ARAUJO, J. D. A. B.; CRUZ, S. H. V. O desenvolvimento da atividade "roda de conversa" em turmas de Educação Infantil. Invest. Práticas, Lisboa , v. 9, n. 2, p. 73-88, set. 2019 . Disponível em $<$ http://www.scielo.mec.pt/scielo.php?script=sci_arttext\&pid=S2182-

$13722019000200005 \&$ lng $=$ pt\&nrm=iso $>$. acessos em 18 jun. 2020. http://dx.doi.org/10.25757/invep.v9i2.166.

PELICIONI, M. C. F. Educação em Saúde e educação ambiental: estratégias de construção da escola promotora da saúde. Tese (Livre-docência). Faculdade de Saúde Publica da USP. São Paulo, 2000. 
PERES, Leidiane de Oliveira; JUDICE, Marcelo Gomes. Percepção ambiental de crianças na escola através da compostagem de resíduos orgânicos. 2017. Trabalho de Conclusão de Curso defendido junto à Faculdade de Engenharia Ambiental da UniRV, Rio Verde, 2017.

PICCININ, P. V. A intencionalidade do trabalho docente com as crianças de zero a três anos na perspectiva Histórico-Cultural. 2012. 76 fls. Trabalho de Conclusão de Curso (Graduação em Pedagogia) - Universidade Estadual de Londrina, Londrina.

PORTILHO, F. Sustentabilidade ambiental, consumo e cidadania. São Paulo: Cortez, 2005.

SEBRAE. EducaçãoSebrae reconhece iniciativas de educação empreendedora no Pará. Agencia Sebrae de noticias, Redação, Belém, 28/06/2019. Disponível em: < http://www.agenciasebrae.com.br/sites/asn/uf/NA/sebrae-reconhece-iniciativas-deeducacao-empreendedora-nopara,74fb16c804b9b610VgnVCM1000004c00210aRCRD>. Acesso em: 20/06/2020.

TRAJBER, R.; SORRENTINO, M. Políticas de Educação Ambiental do Órgão Gestor. In: Vamos cuidar do Brasil : conceitos e práticas em educação ambiental na escola. Brasília: Ministério da Educação, Coordenação Geral de Educação Ambiental: Ministério do Meio Ambiente, Departamento de Educação Ambiental : UNESCO, 2007.

UNICEF. O mundo não consegue proporcionar às crianças uma vida saudável e um clima adequado para o seu futuro: OMS-UNICEF-Lancet. UNICEF, Brasil, 2020. Disponível em: <https://www.unicef.org/brazil/comunicados-de-imprensa/omundo-nao-consegueproporcionar-as-criancas-uma-vida-saudavel-e-um-climaadequado >. Acesso em: 18/06/2020.

VAS, L. M. S. Diagnóstico dos resíduos sólidos produzidos em uma feira livre: 0 caso da Feira do tomba. Feira de Santana: Sitientibus, 2003. 
VELOSO, N. Entre camelos e galinhas, uma discussão acerca da vida na escola. In: Vamos cuidar do Brasil : conceitos e práticas em educação ambiental na escola. Brasília: Ministério da Educação, Coordenação Geral de Educação Ambiental: Ministério do Meio Ambiente, Departamento de Educação Ambiental : UNESCO, 2007.

Enviado: Junho, 2020.

Aprovado: Agosto, 2020. 